THE LANGUAGE LABORATORY AND TEFL SOFTWARE: A PROGRAM THAT WORKS

by Walter F. Davison

The English Language Institute (ELI) at the University of Pittsburgh has for several years been experimenting with various types of recorded materials and formats in the language laboratory for use in its intensive English language program. These materials have generally been easily available commercially prepared tapes plus some materials produced with language lab equipment. We now have what I believe to be a viable language laboratory program which may be of interest not only to schools which have similar TEFL programs but to institutions with programs involving other languages as well.

The ELI program at the University of Pittsburgh offers courses in English for students who have at least completed high school and whose native language is not English. The basic course meets twenty hours per week including four fifty-minute periods in the laboratory. An intermediate course meets twelve hours a week including four full periods in the laboratory. The great amount of time scheduled for the laboratory each day puts pressure on those instructors who are responsible for lab classes to work out useful programs. ${ }^{1}$ The necessity for both software and planning for the lab class quickly becomes obvious. Hence, the conditions for a rapid development of language laboratory materials and planning are present.

We feel that the key to the development of successful lab programs lies in the maintaining of student interest throughout the entire fifty-minute period. ${ }^{2}$ Student interest can be maintained in the laboratory for the full class period under the following conditions:

The actual programs have been developed by the staff of ELI: those people who have been primarily responsible for working out these programs are Dorothea Gottlieb Akand, Sharon Hawryluk, and Judy Vernick.

${ }^{2}$ Note that a fifty-minute program is far in excess of the amount of time recommended by several authorities on usage of language laboratories: Edward M. Stack in The Language Laboratory and Modern Languag Teaching recommends one-half rour (p.226); Joseph C. Hutchinson in Trends in Language Teaching (Albert Valdman, ed.) states that sessions should "in no case (be) longer than thirty minutes. "(p. 224); Philip D. Smith and Emanuel Berger refer to a "recommended 15-20 minutes of daily oral practice" in An Assessment of Three Foreign Language Teaching Strategies Utilizing Three Language Laboratory Systems (p. 4). 


\section{Language Laboratory and TEFL Software}

(1) software is available which is appropriate for the level and skill being taught

(2) the taped materials are utilized to effect a varied program

(3) a regular teacher demonstrates the importance of the lab class by monitoring the students in the lab. 3

(1) The Language Laboratory at the University of Pittsburgh has accumulated a relatively large number of English language tape series for use in ELI programs. There are currently nine different series that are being used in both the basic and intermediate classes. Each of these nine series are listed below according to languagelearning activities. The predominant drill types for these activities is also specified since they have a bearing on the organization of the lab program.

I. Grammar tapes

a) mechanical drills

b) meaningful drills ${ }^{4}$

Texts: $M M C$ by Bruder

Modern English by Rutherford

II. Pronunciation tapes

repetition drills

Texts: Sound to Speech by Davison

Pronunciation Drills by Trager and Henderson

III. Aural comprehension tapes

a) dictation

b) following instructions

c) answering questions on brief narratives

Texts: Improving Aural Comprehension by Morley

Listen and Guess by Allen and Allen

Punctuation and Mechanics of Writing by Jaramillo

Brief locally recorded oral science readings for comprehension questions

3 Alfred S. Hayes in Hocking's Language Laboratory and Longuage Learning refers to "the very great importance of providing the student with frequent opportunities to demonstrate before a prestige person what he has learned." (p. 68).

See Christina Bratt Paulston, "Structural Pattern Drills: A Classifcation," Foreign Language Annals, IV, 2 (Dec., 1970), 284-289, for an important discussion of drill types. Paulston divides grammar drills into three types: mechanical, meaningful, and communicative. The recorded materials for Bruder's text consist primarily of mechanical drills. The Rutherford materials emphasize meaningful drills and are much more difficult. 
IV. Grammar plus pronunciation (rhythm, stress, intonation) contemporary popular songs coordinated with grammatical patterns currently being studied

(2) Each of these series is divided into short and usually selfcontained units which are given in combination with units from other series while maintaining a close coordination with regular classroom activities, particularly in grammar and pronunciation. Thus, a single day's language lab program for the basic course might consist of units for the following skills:

1. AURAL COMPREHENSION (dictation and following directions) Aural Comprehension (Morley) . . . . . . . . $7 \mathrm{~min}$.

2. GRAMMAR (mechanical and meaningful drills) MMC (Bruder) . . . . . $9 \mathrm{~min}$.

3. AURAL COMPREHENSION (dictation and following directions) Listen and Guess (Allen and Allen) . . . . . . $11 \mathrm{~min}$

4. PRONUNCIATION (repetition drills) Sound to Speech (Davison) . . . . . . $10 \mathrm{~min}$.

5. POPULAR SONGS coordinated with grammatical patterns being taught . . . . $8 \mathrm{~min}$. A lab program for an intermediate-level class would be typified by units for these language skills:

1. AURAL COMPREHENSION (dictation and following directions) Aural Comprehension (Morley) . . . . . $8 \mathrm{~min}$.

2. GRAMMAR (mechanical and meaningful drills) Modern English (Rutherford) . . . . $12 \mathrm{~min}$.

3. AURAL COMPREHENSION (answering questions on brief narratives)

Science readings (locally produced) . . . $10 \mathrm{~min}$.

4. AURAL COMPREHENSION (dictation and following directions)

Aural Comprehension (Morley) . . . . 9 min.

The average length of each lab unit will depend on the series, but the usual length of the units is less than eleven or twelve minutes. The Morley aural comprehension tapes, for example, average from seven to nine minutes for 132 units. The large number of units for this particular series enables us to use these tapes for both basic and intermediate classes. Because each unit of every series used in an ELI lab program is short, a variety of activities may be introduced and the interest level of the students remains high. Before the 


\section{Language Laboratory and TEFL Software}

stucients have an opportunity to become bored, the activity has been changed: the tape may proceed from mechanical repetition to following directions and then to mechanical and meaningful grammatical drills. It may then go back to following directions and then to comprehension questions or to singing along with Pete Seeger or the Rolling Stones.

The combinations of units are limited only by the drill types which predominate in each unit and by current activities in the classroom. We try not to have the same activity or drill type in two consecutive tapes. The emphasis we give to aural comprehension in the laboratory is evidenced by the amount of time devoted to it.4 The laboratory is, of course, particularly well-suited for aural comprehension activities, and we take advantage of this factor in planning the programs.

(3) The role of the teacher in the lab is twofold. First, he must select and arrange the units which are available into a cohesive program. That is his easy task. His second task, a more difficult one, is to spark the students interest in the subject matter so that they really want to learn the material. One way he can do this is by showing a genuine interest in the students progress as well as in the materials. In the lab, the teacher monitors the students as they work through the program. When our instructors monitor, they rarely try to correct a student's response during the program as it disrupts the sequence of the drill. What they do instead is to encourage the student by quickly inserting "good " or "right" and thereby show interest in the student's work. If serious mistakes are being made by the students, the lab class is not the place to try to correct them. Corrective work takes place in the classroom where there is time enough to do an adequate job.

Lab classes are usually flexible. The teacher may change the order of the series from day to day for even more variety, or units from other series may be substituted depending on the successes or difficulties in the regular classroom. The flexibility of the lab class is an important factor in maintaining variety.

It should be noted that we do not make use of our record/playback/compare facilities in the ELI classes because the fast pace and variety of the program would be lost. Furthermore, aural comprehension materials do not lend themselves to repetition unless remedial

45. Belasco in "Where is Programmed Language Instruction Most Effective," a paper presented at the Kentucky Foreign Language Conference. Lexington, Kentucky, April, 1969, writes, "The key to achieving real proficiency in speaking properly lies in achieving real proficiency in listening comprehension." (p. 10). 
work is called for. Students are encouraged to come to the lab on their own time when remedial work is needed. At that time they may, should they wish, record and compare their responses for grammar and pronunciation tapes. Many students do exactly this, but the core program utilizes only a broadcast system with audio-active equipment.

In sum, the effect of good software, careful planning for a variety of activities keyed to the classroom, the presence and genuine interest of a regular teacher, plus a smile, seem to work linguistic wonders that we believe can be replicated with relative ease in any institution with minimal hardware facilities. The emphasis here is clearly on software.

ABOUT THE AUTHOR: Walter F. Davison is Director of the Language Laboratory at the University of Pittsburgh in Pennsylvania.

REFERENCES CITED

BELASCO, S. "Where is Programmed Language Instruction Most Effective?" Paper presented at the Kentucky Foreign Language Conference, Lexington, Kentucky, April, 1969. ERIC Document ED 030852.

HAYES, ALFRED S. In Elton Hocking, Language Laboratory and Language Learning. Monograph No. 2. Washington, D.C.: Department of Audiovisual Instruction, National Education Association of the United States, 1967.

HUTCHINSON, JOSEPH C. "The Language Laboratory: Equipment and Utilization." Trends in Language Teaching. Albert Valdman, Ed. New York: McGraw-Hill Company, 1966.

SMITH, PHILLIP D. JR. and EMANUEL BERGER. An Assessment of Three Foreign Language Teaching Strategies Utilizing Three Language Laboratory Systems. Washington, D.C.: U.S. Department of Health, Education, and Welfare, Office of Education, Bureau of Research, January, 1968.

STACK, EDWARD M. The Language Laboratory and Modern Language Teaching. New York: Oxford University Press, 1971.

ENGLISH MATERIALS CITED (with number of recorded units and minute per unit average)

ALLEN, DOBERT L. and VIRGINIA FRENCH ALLEN. Listen and Guess! New York: McGraw-Hill Book Company, 1965. (48 units, 6-7 $\mathrm{min}$. average/unit) 
BURDER, MARY N. MMC: Drilling for Oral Proficiency in English. Pittsburgh: English Language Institute, University of Pittsburgh, 1972. (86 units, 7-9 min. average/unit)

Contemporary popular songs coordinated with grammar lessons in $M M C$. (approximately 50 selections)

DAVISON, WALTER F. Sound to Speech: A Pronunciation Manual for English as a Foreign Language. Pittsburgh: English Language Institute and University Center for International Studies, University of Pittsburgh, 1973. (38 units, 8-9 min average/unit)

JARAMILLO, BARBARA LAUSBERG. Punctuation and Mechanics of Writing. Pittsburgh: English Language Institute and University Center for International Studies, University of Pittsburgh, 1973. ( 30 units, $5 \mathrm{~min}$. average/unit)

MORLEY, JOAN. Improving Aural Comprehension. Ann Arbor: The University of Michigan Press, 1972. (132 units, 6-8 min. average/ unit)

RUTHERFORD, WILLIAM E. Modern English: A Textbook for Foreign Students. New York: Harcourt, Brace \& World, Inc., 1968. (20 units, $10 \mathrm{~min}$. average/unit)

SCIENCE READINGS FOR AURAL COMPREHENSION. (recorded locally) ( 48 units, $2-3 \mathrm{~min}$. average/unit - played 2 or 3 times)

TRAGER, EDITH CROWELL and SARA COOK HENDERSON. Pronunciation Drills for Learners of English. Rockville, Maryland: English Language Services, 1972. (39 units, 9-10 min. average/ unit) 